\title{
Text Mining dan Klasterisasi Sentimen Pada Ulasan Produk Toko Online
}

\author{
Rimbun Siringoringo ${ }^{1 *}$, Jamaluddin ${ }^{2}$ \\ Address : Universitas Methodist Indonesia, Manajemen Informatika, Indonesia ${ }^{1,2}$ \\ Email : rimbun.ringo@gmail.com ${ }^{1}$,jac.satuno@gmail.com² \\ * Corresponding author
}

\begin{abstract}
Abstrak
Pertumbuhan media sosial dan e-commerce mengubah cara berinteraksi dan menyampaikan pandangan, opini dan mood. Ulasan produk merupakan salah satu bentuk penyampaian opini dan sentimen konsumen terhadap sebuah produk secara online. Ulasan produk saat ini memiliki peranan yang sangat penting dalam mempengaruhi minat konsumen terhadap sebuah produk. Analisis sentimen merupakan pendekatan yang banyak dikerjakan untuk mengekstrak informasi dan menggali opini berkaitan dengan ulasan produk. Analisis sentimen memiliki beberapa tantangan, yang pertama sering sekali hasil analisis sentimen yang dihasilkan oleh model-model prediksi berbeda dengan sentimen yang aktual, tantangan kedua adalah berkaitan dengan cara konsumen mengekpresikan sentimen dan mood selalu berbeda dari satu keadaan ke keadaan berikutnya. Pada penelitian ini dilakukan analisis sentimen berdasarkan ulasan produk sepatu Trendy Shoes merek Denim. Tahapan analisis sentimen terdiri dari pengumpulan data, pemrosesan awal, transformasi data, seleksi fitur dan tahapan klasifikasi menggunakan Suppport Vector Machine.

Pemrosesan awal menerapkan tahapan text mining yakni case folding, non alpha numeric removal, stop words removal, dan stemming. Hasil analisis sentimen diukur menggunakan kriteria Akurasi, G-Mean, dan F-Measure. Dengan menerapkan pengujian pada tiga jenis data sentimen diperoleh hasil bahwa Suppport Vector Machine dapat mengklasifikasi sentimen dengan baik. Performa Suppport Vector Machine dibandingkan dengan metode $K$-Nearest Neighor. Hasil klasifiasi sentimen menggunakan Suppport Vector Machine lebih unggul dari K-Nearest Neighbor.
\end{abstract}

Keywords - sentiment analysis, text mining, support vector machine, product review

\section{Pendahuluan}

Hasil riset yang diadakan oleh lembaga riset Marketing Research (Nielsen, 2014), mengemukakan fakta bahwa sebanyak $71 \%$ masyarakat pengguna internet saat ini melakukan survei sebelum melaukan aksi jual-beli secara online. Ulasan produk memiliki pengaruh yang sangat besar dalam mempengaruhi minat konsumen. Berdasarkan hasil riset dari Dimensional Research, terdapat $91 \%$ calon pembeli memutuskan untuk membeli produk karena dikuatkan oleh ulasan produk positif, sebesar $86 \%$ calon pembeli memutuskan untuk tidak membeli produk tertentu karena dikuatkan oleh ulasan produk negatif [1].

Analisis sentimen merupakan studi dalam rangka menganalisis opini, emosi, dan sentimen masyarakat terkait suatu hal [2]. Analisis Sentimen menerapkan Natural Language Processing (NLP) dan text mining dalam mengidentifikasi dan mengekstrak informasi tentang topik tertentu [3]. Mengingat

Program Studi Teknik Informatika Universitas Prima Indonesia (UNPRI) Medan perkebambangan media sosial, e-commerce, dan blog, saat ini analisis sentimen penting bagi kehidupan sosial-ekonomi masyarakat.

Ada dua tantangan utama dalam melakukan analisis sentimen, pertama sering sekali bahwa sentimen yang dihasilkan oleh model-model prediksi berbeda dengan sentimen yang aktual, kedua cara konsumen mengekpresikan emosi dan sentimen selalu berbeda beda dari waktu ke waktu [4]

Data mining dan text mining menawarkan pendekatan komputasional dalam menganalisis sentimen. Data mining juga telah menjadi pendekatan yang paling populer saat ini untuk menggali opini publik [5]. Beberapa penelitian terkait penerapan data mining pada sentimen analisis adalah penerapan Naive Bayes Classifier [2] pada analisis sentimen terhadap produk buku dan elektronik berdasarkan ulasan produk yang dikumpulkan dari situs jual beli Amazon.com. Penerapan metode $K$-Means Clustering (KMC) dan 
Decision Tree pada analisis sentimen untuk mengidentifikasi opini konsumen terhadap produk baru [6]. Metode Support Vector Machine (SVM) diterapkan pada analisis sentimen terhadap film boxoffice berdasarkan ulasan produk pada situs imdb.com [4]

\section{Studi Literatur}

\subsection{Analisis Sentimen}

Salah satu gol dari analisis sentimen adalah mengidentifikasi, menggali, serta mengekstrak opini publik terkait dengan topik tertentu [7], sehingga analisis sentimen sering juga dikenal dengan istilah opinion mining [2]. Salah satu masalah pada analisis sentimen adalah bagaimana menentukan kategori sentimen pada teks, apakah positif atau negatif.

\subsection{Text Mining}

Analisis sentimen dan text mining merupakan dua hal yang tidak dapat dipisahkan terutama jika melakukan analisis sentimen pada media online. Text mining merupakan studi yang lebih sfesifik pada data mining untuk mengungkap pola yang tersembunyi pada teks, sehingga ketika analisis sentimen dan text mining dipadukan pada penggalian opini, akan dihasilkan alat bantu yang sangat baik dan andal [7].

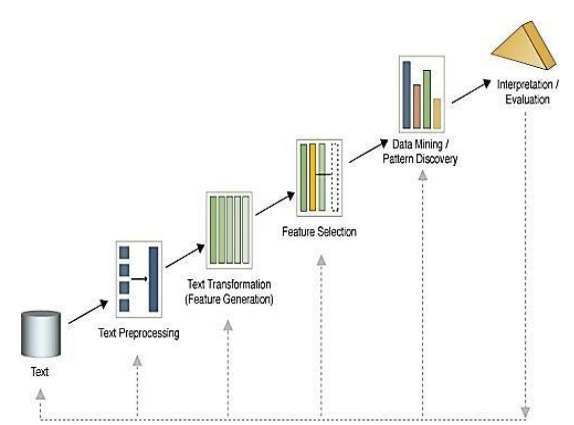

Gambar 1. Alur text mining

Berdasarkan gambar 1, alur text mining pada umumnya adalah tahap pengumpulan teks, pemrosesan awal atau text pre-processing, transformasi teks atau text trasformation, seleksi fitur atau feature selection, data mining dan interpretasi [8] Keseluruhan tahapan tersebut akan menjadi acuan pada penelitian ini.

Pemrosesan awal data atau text pre-processing terdiri dari case folding, non alpha numeric removal, stop words removal, dan stemming. Tahap case folding bertujuan untuk mengubah bentuk teks kedalam bentuk huruf kecil, non alpha numeric removal bertujuan untuk menghilangkan semua karakter selain karakter alfanumerik, seperti !, @, \&, dan yang lainnya. Stop words adalah kata-kata yang bukan merupakan ciri (kata unik) dari suatu dokumen seperti kata sambung atau kata kepunyaan, stop words removal bertujuan untuk menghilangkan daftar stop words dari dokmen. Stemming bertujuan untuk mengembalikan sebuah kata ke dalam bentuk dasarnya, misalnya kata mempermainkan menjadi main, peranan menjadi peran. Selanjutnya dilakukan transformasi data untuk mengubah data string menjadi numerik agak dapat diproses oleh algoritma machine learning

\subsection{Support Vector Machine}

Secara sederhana konsep Support Vector Machine (SVM) dapat dijelaskan sebagai usaha mencari hyperplane-hyperplane terbaik yang berfungsi sebagai pemisah dua buah kelas pada input ruang vektor

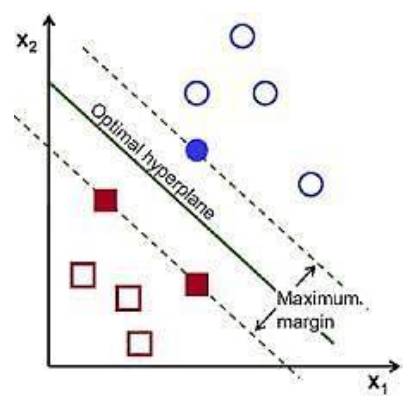

Gambar 2 Hyperlane pada SVM

Gambar 2 memperlihatkan beberapa pola yang merupakan anggota dari dua buah kelas yaitu +1 dan -1 . Warna merah merupakan representasi dari kelas -1 , warna biru merupakan representasi dari kelas +1. Pekerjaan klasifikasi merupakan usaha menemukan garis (hyperplane) yang memisahkan antara kedua kelompok tersebut.

Garis putus-putus berfungsi sebagai alternatif garis pemisah antar kelas. Hyperplane pemisah terbaik antara kedua kelas dapat ditentukan dengan mengukur margin hyperplane tersebut dan mencari titik maksimalnya [2]. Margin adalah jarak antara hyperplane tersebut dengan pattern terdekat dari masing-masing kelas. Pola yang paling dekat ini disebut sebagai support vector [9]. Garis tebal lurus pada gambar 2 menunjukkan hyperplane yang terbaik, yaitu yang terletak tepat pada tengah-tengah kedua kelas, sedangkan titik merah dan kuning yang berada dalam lingkaran hitam adalah support vector. Usaha untuk menemukan posisi hyperplane ini merupakan ide utama dari SVM.

\section{METODOLOGI}

\subsection{Prosedur kerja}

Prosedur kerja penelitian ditampilkan pada gambar 3 . Data ulasan produk yang digunakan bersumber dari beberapa situs e-commerce yang ada di indonesia. 


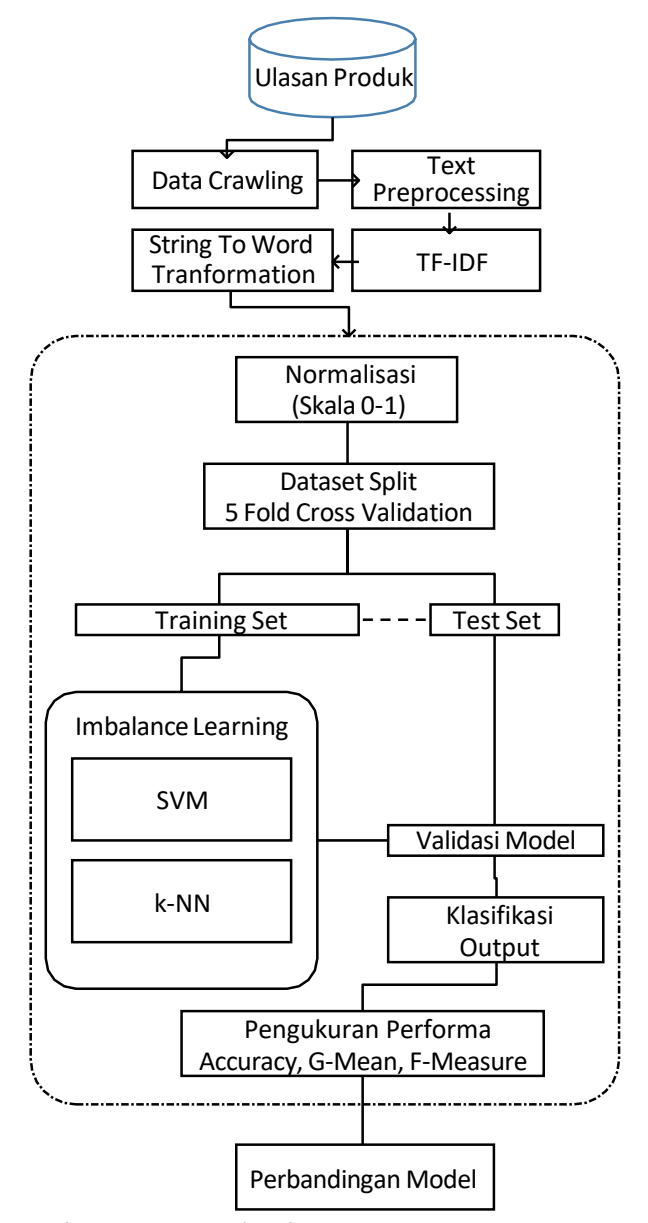

Gambar 3. Prosedur kerja

\subsection{Data penelitian}

Penelitian ini menggunakan data ulasan produk yang dikumpulkan dari beberapa situs jual beli online di Indonesia. Pada gambar 2 berikut ini disajikan contoh ulasan produk TrendyShoes sepatu anak merek Denim.

Tabel 1 Sampel acak ulasan produk awal

\begin{tabular}{|c|c|}
\hline Id & Uasan Produk \\
\hline 27 & $\begin{array}{l}\text { Sepatunya bagus. tetapi ukuran nya kecil } \\
\text { dari ukuran biasanya. Jd mesti pesan } \\
\text { ukuran lebih besar dari ukuran biasanya }\end{array}$ \\
\hline 81 & kiriman cepat sampai, â€!.BARANG SESUAI \\
\hline 89 & $\begin{array}{l}\text { Anak saya pas dipesan tidak mau..tapi } \\
\text { ketika barang nya datang, dia suka bangat. }\end{array}$ \\
\hline 39 & beda sama yang digambar..! \\
\hline 120 & warna kurang sesuai dengan gambar \\
\hline 16 & 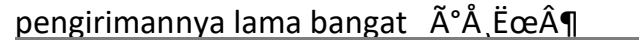 \\
\hline 71 & SANGAT SANGAT KECEWA! \\
\hline
\end{tabular}

\subsection{Pemrosesan awal data}

Setelah data ulasan produk berhasil di kumpulkan, ${ }_{4}$ maka tahap selanjutnya adalah tahap pemrosesan Program Studi Teknik Informatika Universitas Prima Indonesia (UNPRI) Medan awal (pre-processing) agar data ulasan produk dapat diterapkan pada algoritma machine learning. Tahapan pre-processing yang diterapkan adalah Case Folding, Non Alpha Numeric Removal, Stop words Removal, dan Stemming. Daftar stop words untuk Bahasa Indonesia terdiri atas 760 kata [10]. Algoritma Stemming yang diterapkan adalah algoritma stemming khusus untuk bahasa Indonesia yaitu algoritma naziefAndriani [11].

Tabel 2 Hasil akhir text pre-processing

\begin{tabular}{|c|c|}
\hline Id & Uasan Produk \\
\hline 27 & $\begin{array}{l}\text { sepatu bagus ukur nya ukur jd mesti pesan } \\
\text { ukur besar ukur }\end{array}$ \\
\hline 81 & kirim cepat barang sesuai \\
\hline 89 & $\begin{array}{l}\text { anak pas pesan barang nya datang suka } \\
\text { bangat }\end{array}$ \\
\hline 39 & beda gambar \\
\hline 120 & warna kurang sesuai gambar \\
\hline 16 & kirim bangat \\
\hline 71 & kecewa \\
\hline
\end{tabular}

\subsection{TF-IDF}

Untuk menentukan bobot setiap fitur pada data ulasan diterapkan algoritma TF-IDF. Hasil penerapan TF-IDF menghasilkan matriks data dengan dimensi 86 atribut x 1073 data. Dimensi data di atas masing sangat besar dan tidak efektif, sehingga atribut yang ada dievaluasi dan difilter.

\subsection{Seleksi fitur data}

Data ulasan produk terdiri atas 71 fitur, jumlah fitur tersebut masih sangat besar karena mengakibatkan dimensi data menjadi terlalu besar. Untuk membuang fitur fitur yang tidak signifikan terhadap proses text mining, dilakukan seleksi fitur menggunakan algoritma Coefficint feature selection (CFS) yang tersedia pada WEKA. Seleksi atribut menghasilkan sebanyak 14 fitur.

Pada tabel terdapat 14 kata kunci yang paling sering muncul di dalam ulasan produk, disusun berdasarkan abjad. Dari 14 kata kunci tersebut, terdapat 6 kata kunci positif dan 8 kata kunci negatif.

Tabel 3 Daftar kata kunci sentimen

\begin{tabular}{lll}
\hline No & keyword & Jenis Sentimen \\
\hline 1 & awet & positif \\
\hline 2 & bagus & positif \\
\hline 3 & besar & negatif \\
\hline 4 & cacat & negatif \\
\hline 5 & cepat & positif \\
\hline 6 & jelek & negatif \\
\hline 7 & kecewa & negatif \\
\hline 8 & lama & negatif \\
\hline
\end{tabular}




\begin{tabular}{|c|c|c|}
\hline 9 & mengelupas & negatif \\
\hline 10 & puas & positif \\
\hline 11 & rusak & negatif \\
\hline 12 & suka & positif \\
\hline 13 & telat & negatif \\
\hline 14 & terimakasih & positif \\
\hline
\end{tabular}

Pada tabel 4 ditampilkan sample 5 fitur atau kata kunci dengan bobot tertinggi TF-IDF. Kata kunci "Bagus" memiliki bobot dengan nilai TF-IDF terkecil yaitu 0,520 .

Tabel 4 Daftar 5 fitur dengan bobot tertinggi data

\begin{tabular}{lll}
\multicolumn{3}{c}{ ulasan produk sepatu } \\
\hline No & Fitur & TF-IDF \\
\hline 1 & Bagus & 0,520 \\
\hline 2 & Sesuai & 1,030 \\
\hline 3 & Terimakasih & 1,236 \\
\hline 4 & Suka & 1,464 \\
\hline 5 & Cepat & 1,588 \\
\hline
\end{tabular}

Penelitian ini menggunakan 3 jenis data ulasan produk. Data ulasan pertama terdiri atas 768 ulasan positif dan 564 ulasan negatif. Data ulasan kedua terdiri atas 768 ulasan positif dan 314 ulasan negatif. Data ulasan ketiga terdiri atas 268 ulasan positif dan 564 ulasan negatif.

Tabel 5 Deskripsi data ulasan

\begin{tabular}{|c|c|c|c|c|c|}
\hline Data & \#Pos & \#Neg & \#Ex & \#IR & \#Atts \\
\hline Ulasan 1 & 768 & 564 & 1332 & 1.36 & 14 \\
\hline Ulasan 2 & 768 & 314 & 1082 & 2.44 & 14 \\
\hline Ulasan 3 & 268 & 564 & 832 & 2.10 & 14 \\
\hline
\end{tabular}

Deskripsi lengkap data ulasan ditampilkan pada tabel 5. Pada tabel tersebut dideskripsikan banyak sentimen positif (\#Pos.), banyak sentimen negatif (\#Neg.), banyaknya data keseluruhan (\#Ex.), tingkat ketidak seimbangan kelas (\#IR.), dan banyaknya atribut (\#Atts)

\subsection{Teknik validasi dan evaluasi}

Teknik evaluasi dan estimasi performa pada penelitian ini menggunakan skema 5-fold cross-validation. Hal ini berarti, dataset ulasan dibagi menjadi 5 bagian atau fold yang sama, setiap fold berisi $20 \%$ dataset, kemudian dilakukan proses learning sebanyak 5 kali. Pada tabel ditampilkan hasil partisi data ulasan1. Teknik evaluasi dan pengukuran performa menerapkan Area Under ROC Curve (AUC). Pertimbangan penggunaan AUC karena AUC secara statistik lebih konsisten. AUC juga lebih baik dari metode akurasi (accuracy) dalam mengevaluasi perbandingan kinerja berbagai algoritma classifier

Program Studi Teknik Informatika

Universitas Prima Indonesia (UNPRI) Medan
Tabel 6 Partisi data ulasan_1

\begin{tabular}{lcll}
\hline Partisi Dataset & $\begin{array}{c}\text { Jumlah } \\
\text { data }\end{array}$ & & Fungsi \\
\cline { 2 - 2 } ulasan1-1tra.dat & 1065 & & Training \\
\hline ulasan1-1tst.dat & 267 & Testing \\
\hline ulasan1-2tra.dat & 1065 & Training \\
\hline ulasan1-2tst.dat & 267 & Testing \\
\hline ulasan1-3tra.dat & 1065 & Training \\
\hline ulasan1-3tst.dat & 267 & Testing \\
\hline ulasan1-4tra.dat & 1065 & Training \\
\hline ulasan1-4tst.dat & 267 & Testing \\
\hline ulasan1-5tra.dat & 1065 & Training \\
\hline ulasan1-5tst.dat & 267 & Testing \\
\hline
\end{tabular}

\subsection{Pengukuran Performa}

Metode pengukuran performa memiliki peranan yang sangat penting untuk mengevaluasi kinerja suatu metode klasifikasi. Confusion matrix merupakan alat yang paling populer dalam mengevaluasi performa klasifikasi. Pada tabel berikut ditampilkan confusion matrix untuk kelas biner, sesuai dengan karakteristik data ulasan yaitu pisitif dan negatif

Tabel 7 Confution Matrix

\begin{tabular}{ccc}
\hline Kelas & $\begin{array}{c}\text { Prediktif } \\
\text { Positif }\end{array}$ & $\begin{array}{c}\text { Prediktif } \\
\text { Negatif }\end{array}$ \\
\hline $\begin{array}{c}\text { Kelas Aktual } \\
\text { Positif }\end{array}$ & TP & FN \\
\cline { 1 - 1 } $\begin{array}{c}\text { Kelas Aktual } \\
\text { Negatif }\end{array}$ & FP & TN \\
\hline
\end{tabular}

True Positive (TP) dan True Negative (TN) merupakan jumlah kelas positif dan negatif yang diklasifikasikan dengan tepat, False Positive (FP) dan False Negative (FN) merupakan jumlah kelas positif dan negatif yang tidak diklasifikasikan dengan tepat. Berdasarkan confusion matrix tersebut dapat ditentukan kriteria performa seperti Accuracy, Precision, Recall, specificity, F-MEASURE, G-Mean dan yang lainnya.

Akurasi (Accuracy) merupakan kriteria yang paling umum untuk mengukur kinerja klasifikasi, tetapi jika bekerja pada kelas tidak seimbang, kriteria ini kurang tepat karena kelas minoritas akan memiliki sumbangsih yang kecil pada kriteria Accuracy. Kriteria Penilaian yang disarankan adalah TPrate, PPvalue, FMEASURE dan G-Mean [7]. F-Measure digunakan untuk mengukur klasifikasi kelas minoritas pada kelas tidak seimbang, dan indeks G-mean digunakan untuk mengukur performa keseluruhan (overall classification 
performance). Pada penelitian ini, performa klasifikasi menggunakan Accuracy, G-Mean, dan F-Measure,

$$
\begin{aligned}
& \text { Recall }=T P_{\text {rate }}=\frac{1}{T P+F N} \\
& \text { Precision }=P P_{\text {value }}=\frac{T P}{T P+F P} \\
& \text { Specificity }=T N_{\text {rate }}=\frac{(2)}{T N+F P} \\
& G-\text { Mean }=\sqrt{T P_{\text {rate }}-T N_{\text {rate }}}
\end{aligned}
$$

\section{Hasil Penelitian}

Pada tabel 8 ditampilkan sampel acak hasil kalsifikasi sentimen ulasan produk menggunakan SVM. Sentimen

\begin{tabular}{|c|c|c|c|c|}
\hline \multirow[t]{2}{*}{ Id } & \multirow[t]{2}{*}{ Ulasan } & \multicolumn{2}{|c|}{ Sentimen } & \multirow[t]{2}{*}{ Ket } \\
\hline & & Aktual & $\begin{array}{l}\text { Prediktif } \\
\text { (SVM) }\end{array}$ & \\
\hline 701 & $\begin{array}{l}\text { ukuran tidak sesuai } \\
\text { sepatu kecil ukur } 35 \\
\text { tidak segitu besar } \\
\text { kecewa berat... }\end{array}$ & Negatif & Positif & FP \\
\hline 62 & $\begin{array}{l}\text { barang bagus sesuai } \\
\text { gambar terimakasih }\end{array}$ & Positif & Positif & TP \\
\hline 714 & $\begin{array}{l}\text { kualitas barang } \\
\text { bagus kirim bagus } \\
\text { bagus }\end{array}$ & Positif & Negatif & FN \\
\hline 603 & $\begin{array}{l}\text { anak suka sepatu } \\
\text { alas kaki dalam tipis } \\
\text { seprtinya tambah } \\
\text { nih alas dalam } \\
\text { lembut nyaman } \\
\text { pakai over all keren } \\
\text { cepat kirim tahan } \\
\text { kualitas layan } \\
\text { terimakasih :-): }\end{array}$ & Positif & Negatif & FN \\
\hline 004 & $\begin{array}{l}\text { sepatu bagus sesuai } \\
\text { gambar besaran } \\
\text { pilih ukur }\end{array}$ & Positif & Positif & TP \\
\hline 015 & $\begin{array}{l}\text { Sepatu tidak sesuai } \\
\text { gambar...!!! bohong } \\
\text { harga mahal: }\end{array}$ & Negatif & Negatif & TN \\
\hline
\end{tabular}
aktual adalah sentimen positif atau negatif yang sesungguhnya.

Tabel 8 Sampel acak klasifiasi ulasan produk

Dengan menggunakan skema validasi 5-fold cross validation, pada tabel 9 ditampilkan jumlah data training yang dikategorikan ke dalam TP, TN, FP, dan FN untuk data ulasan_1.

Tabel 9 Hasil validasi 5-fold CV data training ulasan_1

\begin{tabular}{|c|c|c|c|c|}
\hline Fold & TP & TN & FP & FN \\
\hline Fold-1 & 612 & 334 & 117 & 2 \\
\hline Fold-2 & 612 & 331 & 120 & 2 \\
\hline
\end{tabular}

Program Studi Teknik Informatika

Universitas Prima Indonesia (UNPRI) Medan

\begin{tabular}{|c|c|c|c|c|}
\hline Fold-3 & 613 & 331 & 121 & 1 \\
\hline Fold-4 & 613 & 332 & 119 & 2 \\
\hline Fold-5 & 614 & 336 & 115 & 1 \\
\hline Rata-rata & $\mathbf{6 1 2 , 8}$ & $\mathbf{3 3 2 , 8}$ & $\mathbf{1 1 8 , 4}$ & $\mathbf{1 , 6}$ \\
\hline
\end{tabular}

Selanjutnya hasil rata-rata data training ada tabel 9 dimasukkan pada tabel 10 untuk menentukan ratarata keseluruhan antara untuk data ulasan_1. Pada tabel 10, rata-rata True Positive (TP) pada data latih (training) sebanyak 612,5 data, rata-rata TP pada uji (testing) sebanyak 153,25 data. Selanjutnya rata-rata TP untuk data ualasan_1 adalah sebesar 382,87 data, rata-rata TN untuk data ulasan_1 adalah 208 data .

Tabel 10 Confusin matrix pengujian data ulasan_1

\begin{tabular}{crrrr}
\hline & \multicolumn{1}{c}{ TP } & \multicolumn{1}{c}{ TN } & \multicolumn{1}{c}{ FP } & \multicolumn{1}{c}{ FN } \\
\hline Training & 612,8 & 332,8 & 118,4 & 1,6 \\
\hline Testing & 153,25 & 84 & 28,75 & 0,5 \\
\hline Rata-rata & 382,88 & 208 & 74 & 1,125 \\
\hline
\end{tabular}

Pada tabel 11, rata-rata True Positive (TP) sebanyak 382,88 data, rata-rata True Negative (TN) sebanyak 118,75 data, rata-rata False Positive (FP) sebanyak

\begin{tabular}{|c|c|c|c|}
\hline & Training & Testing & Rata-rata \\
\hline TP & 612,5 & 153,25 & 382,88 \\
\hline TN & 189,75 & 47,75 & 118,75 \\
\hline FP & 61,5 & 15 & 38,25 \\
\hline FN & 1,75 & 0,5 & 1,13 \\
\hline
\end{tabular}
38,25 data, dan rata-rata False Negative (FN) sebanyak 1,13 data.

Tabel 11 Confusin matrix pengujian data ulasan_2

Pada tabel 12, rata-rata True Positive (TP) sebanyak 9,75 data, rata-rata True Negative (TN) sebanyak 279,13 data, rata-rata False Positive (FP) sebanyak 2,63 data, dan rata-rata False Negative (FN) sebanyak 35,25 data.

Tabel 12 Confusin matrix pengujian data ulasan_3

\begin{tabular}{crrrr}
\hline & TP & \multicolumn{1}{c}{ TN } & \multicolumn{1}{c}{ FP } & FN \\
\hline Training & 158 & 446,5 & 4,25 & 56,25 \\
\hline Testing & 39,5 & 111,75 & 1 & 14,25 \\
\hline Rata-rata & 98,75 & 279,13 & 2,63 & 35,25 \\
\hline
\end{tabular}

Pada tabel 13, tabel 14, dan tabel 15 ditampilkan performa SVM pada klasifikasi sentimen pada data ualasn_1, ulasan_2, dan ulasan_3. Hasil SVM dibandingkan dengan metode $K$-Nearest Neighbor (KNN). Dari ke tiga tabel tesebut hasil klasifikasi Sentimen menggunakan SVM lebih baik dari K-NN.

Tabel 13 Performa klasifikasi data ulasan_1

$$
\begin{array}{lrl} 
& \multicolumn{1}{l}{\text { SVM }} & \text { KNN } \\
\text { Accuracy } & \underline{88,83 \%} \quad \underline{73,99 \%}
\end{array}
$$




\begin{tabular}{lrr}
\hline G-Mean & $85,91 \%$ & $83,70 \%$ \\
\hline F-Measure & $91,15 \%$ & $87,44 \%$ \\
\hline
\end{tabular}

Tabel 14 Performa klasifikasi data ulasan_2

\begin{tabular}{lrr} 
& \multicolumn{1}{c}{ SVM } & \multicolumn{1}{l}{ KNN } \\
\hline Accuracy & $92,65 \%$ & $78,66 \%$ \\
\hline G-Mean & $86,71 \%$ & $83,23 \%$ \\
\hline F-Measure & $95,07 \%$ & $83,09 \%$
\end{tabular}

Tabel 15 Performa klasifikasi data ulasan_3

\begin{tabular}{lrr} 
& SVM & KNN \\
\hline Accuracy & $90,80 \%$ & $87,61 \%$ \\
\hline G-Mean & $85,30 \%$ & $80,48 \%$ \\
\hline F-Measure & $83,71 \%$ & $77,51 \%$ \\
\hline
\end{tabular}

\section{Kesimpulan}

Pada penelitiaan ini dilakukan analisis sentimen dan text mining pada ulasan produk. Data ulasan produk yang dikumpulkan kemudian dibagi menjadi tiga data yaitu ulasan_1, ulasan_2, dan ulasan_3. Ketiga data ulasan tersebut memiliki tingkat ketidak seimbangan kelas yang berbeda yaitu 1, 36; 2, 44 dan 2,10. Dengan menerapkan pengujian pada tiga jenis data sentimen yan berbeda diperoleh hasil bahwa Suppport Vector Machine dapat bekerja dengan baik pada data ulasan tidak seimbang. Performa Suppport Vector Machine dibandingkan dengan metode $K$-Nearest Neighor. Hasil klasifiasi sentimen menggunakan Suppport Vector Machine lebih unggul dari $K$ Nearest Neighor

\section{References}

[1] Y. E. Ariska, W. Maharani, and M. S. Mubarok, "Peringkasan review produk berbasis fitur menggunakan semantic similarity scoring dan sentence clustering," p. 9.

[2] X. Fang and J. Zhan, "Sentiment analysis using product review data," Journal of Big Data, vol. 2, no. 1, p. 5, 2015.

[3] P. Kowalchuk, "Implementing a Drilling Reporting Data Mining Tool Using Natural Language Processing Sentiment Analysis Techniques," in SPE Middle East Oil and Gas Show and Conference, 2019.

[4] P. Nagamma, H. R. Pruthvi, K. K. Nisha, and N. H. Shwetha, "An improved sentiment analysis of online movie reviews based on clustering for boxoffice prediction," in Computing, Communication \& Automation (ICCCA), 2015 International Conference on, 2015, pp. 933-937.

[5] A. Amolik, N. Jivane, M. Bhandari, and M.

[6] Venkatesan, "Twitter sentiment analysis of movie reviews using machine learning techniques," international Journal of Engineering and Technology, vol. 7, no. 6, pp. 1-7, 2016.

[7] R. Soni and K. J. Mathai, "Effective sentiment analysis of a launched product using clustering and decision trees," International Journal of Innovative Research in Computer and Communication Engineering, vol. 4, no. 1, 2016.

[8] H. Isah, P. Trundle, and D. Neagu, "Social media analysis for product safety using text mining and sentiment analysis," in 2014 14th UK Workshop on Computational Intelligence (UKCI), 2014, pp. 1-7.

[9] L. Kumar and P. K. Bhatia, "Text Mining: Concepts, Process and Applications," Journal of Global Research in Computer Science, vol. 4, no. 3, pp. 36-39, 2013.

[10] I. C. R. Drajana, "Metode support vector machine dan forward selection prediksi pembayaran pembelian bahan baku kopra," vol. 9, p. 8, 2017.

[11] F. Z. Tala, "A study of stemming effects on information retrieval in Bahasa Indonesia," Institute for Logic, Language and Computation, Universiteit van Amsterdam, The Netherlands, 2003.

[12] M. Adriani, J. Asian, B. Nazief, S. M. Tahaghoghi, and H. E. Williams, "Stemming Indonesian: A confix-stripping approach," ACM Transactions on Asian Language Information Processing (TALIP), vol. 6, no. 4, pp. 1-33, 2007.

[13] W. Prachuabsupakij and P. Doungpaisan, "Matching preprocessing methods for improving the prediction of student's graduation," in Computer and Communications (ICCC), 2016 2nd IEEE International Conference on, 2016, pp. 3337. 